\title{
BMJ Open Nutritional rickets in Norway: a nationwide register-based cohort study
}

\author{
Haakon E Meyer, ${ }^{1,2}$ Kristina Skram, ${ }^{3}$ Ingvill Almås Berge, ${ }^{3}$ Ahmed A Madar, ${ }^{1}$ \\ Hilde Johanne Bjørndalen ${ }^{3}$
}

To cite: Meyer HE, Skram K, Berge IA, et al. Nutritional rickets in Norway: a nationwide register-based cohort study. BMJ Open 2017;7:e015289. doi:10.1136/ bmjopen-2016-015289

- Prepublication history and additional material are available. To view these files please visit the journal online (http://dx.doi org/10.1136/bmjopen-2016015289).

Received 29 November 2016 Revised 4 April 2017 Accepted 4 April 2017

CrossMark

${ }^{1}$ Department of Community Medicine and Global Health, University of Oslo, Oslo, Norway ${ }^{2}$ Division of Mental and Physical Health, Norwegian Institute of Public Health, Oslo, Norway ${ }^{3}$ Department of Pediatrics, 0slo University Hospital, Oslo, Norway

Correspondence to Professor Haakon E Meyer; haakon.meyer@fhi.no

\begin{abstract}
Objectives Poor vitamin D status has been reported to be highly prevalent in many non-western immigrant groups living in Norway and other western countries. However, data on rickets are scarce, and the aim of the current study was to identify new cases of nutritional rickets in Norway in the period 2008-2012 among children under the age of 5 years.

Design Register-based cohort study.

Setting The Norwegian population from 2008 to 2012.

Participants Children with nutritional rickets under the age of 5 years.
\end{abstract}

Main outcome measure Nutritional rickets. Patients with ICD10 (International Statistical Classification of Diseases and Related Health Problems, 10th revision) diagnosis code E55.0 (active rickets) treated at all Norwegian hospitals were identified in the Norwegian Patient Registry. We were able to review $85 \%$ of the medical records for diagnosis confirmation. In addition, we identified patients with the diagnoses E55.9, E64.3 and E83.3 to identify individuals with rickets who had been given other diagnoses.

Results Nutritional rickets was confirmed in 39 children aged $0-4$ years with the diagnosis of E55.0. In addition, three patients with the diagnosis of unspecified vitamin D deficiency (E55.9) were classified as having nutritional rickets, giving a total of 42 patients. Mean age at diagnosis was 1.40 years (range $0.1-3.5$ years), and $93 \%$ had a non-western immigrant background. The incidence rate of rickets was estimated to be 0.3 per 10000 person-years in the total Norwegian child population under the age of 5 years and 3.1 per 10000 person-years in those with an immigrant background from Asia or Africa.

Conclusion The number of children with nutritional rickets in Norway remained low in the period 2008-2012. Nearly all children had a non-western immigrant background.

\section{INTRODUCTION}

The classical consequence of vitamin D deficiency is nutritional rickets in children. Nutritional rickets is caused primarily by severe vitamin D deficiency and/or a low intake of calcium. ${ }^{1}$ Poor vitamin D status has been reported in many non-western immigrant groups living in western countries. ${ }^{2}$ In the Oslo Health Study, $43 \%$ of the non-western immigrant women and $31 \%$ of the men had vitamin $\mathrm{D}$ deficiency with
Strengths and limitations of this study

- This register-based study covered the complete Norwegian population.

- All children under the age of 5 years with a diagnosis code of rickets were identified.

- The diagnosis was confirmed by medical record review at the treating hospital.

- We were not able to review the medical records for $15 \%$ of the patients.

- The study was limited to patients treated in the period 2008-2012.

circulating 25-hydroxyvitamin D $(25(\mathrm{OH})$ D) $<25 \mathrm{nmol} / \mathrm{L},{ }^{3}$ and $21 \%$ of women born in Pakistan had severe vitamin D deficiency $(25(\mathrm{OH}) \mathrm{D}<12.5 \mathrm{nmol} / \mathrm{L}) .{ }^{4}$ The poor vitamin $\mathrm{D}$ status among women of childbearing age was confirmed in a study among immigrant mothers (6 weeks after giving birth) with a background from Pakistan, Turkey and Somalia living in Oslo. ${ }^{5}$ Fifty-six per cent had vitamin $\mathrm{D}$ deficiency, and $15 \%$ had severe vitamin $\mathrm{D}$ deficiency. Based on the poor vitamin $\mathrm{D}$ status of the adults, it has been a concern that rickets could emerge as a large problem among infants with an immigrant background. In addition, the immigrant part of the population has increased and currently nearly $10 \%$ of all Norwegian children under the age of 5 years have a non-western immigrant background. ${ }^{6}$ Data about rickets in Norway and other European countries are scarce. An enquiry sent to all hospitals with paediatric wards in 2000 reported 65 children with nutritional rickets in Norway during the 2years period of 1998-1999, of which $83 \%$ had an immigrant background. ${ }^{7}$ Eighty per cent were younger than 3 years. In a study covering southern Denmark from 1985 to 2005, only 112 patients with nutritional rickets were identified during a 20-year period, of which $75 \%$ had an immigrant background. ${ }^{8}$ In a population-based study from Olmsted County, Minnesota, $76 \%$ of the cases with nutritional rickets had a non-white 
ethnic background. Although the incidence was low, it increased in the period 1970-2009. ${ }^{9}$ A study reporting hospital admissions for rickets in England across five decades also suggests that the incidence of rickets has increased during recent years. ${ }^{10}$ In that study, the diagnoses were not confirmed by a medical record review, but hospital-based studies from the UK indicate that rickets might be an increasing problem among immigrant children. ${ }^{11} 12$

Prior to this study, no updated information on the occurrence of rickets in Norway was available. However, several efforts to secure a good vitamin D status among children have been introduced in recent years, including free vitamin $\mathrm{D}$ drops for infants with a non-western immigrant background and infant food fortified with vitamin $\mathrm{D}$. The aim of the study was to identify new cases of nutritional rickets in children under the age of 5 years in the Norwegian population in the period 2008-2012.

\section{MATERIALS AND METHODS}

The national specialist healthcare register (Norwegian Patient Registry (NPR)) contains information on all hospital admissions and outpatient contacts in the specialised health services. The register also includes the unique 11-digit personal identification number provided to all Norwegian residents. We used data from the NPR in the period 2008-2012 and identified all admissions/ contacts with the diagnosis E55.0 (active rickets), which is a subcode of E55, vitamin D deficiency. In addition, we identified admissions/contacts with the diagnosis E55.9 (unspecified vitamin D deficiency), E64.3 (sequelae of rickets) and E83.3 (disorders of phosphorus metabolism and phosphatases) to identify patients with rickets who had been given other diagnoses. Data extraction was performed by the NPR, and we did not have access to the background data.

To verify the diagnosis, all hospitals treating the children were contacted. At each responding hospital, doctors in the paediatric department completed a questionnaire for medical record review. We requested information about X-ray findings, biochemical tests, symptoms, the clinical examination and the child's ethnic background. In addition, the type and effect of treatment was requested. Finally they were asked if the diagnosis was rickets, and if so, if it was nutritional rickets.

To reconfirm the conclusions, two doctors (KS and IAB) working at the paediatric department at Oslo University Hospital reviewed all the questionnaires (half each). The diagnosis of nutritional rickets was based on biochemical markers and clinical symptoms/signs and/ or radiological findings. In addition, it was taken into account if it was reported that the patient responded favourably to treatment with vitamin $\mathrm{D}$. The following biochemical criteria were used: $25(\mathrm{OH}) \mathrm{D}<12.5 \mathrm{nmol} / \mathrm{L}$ or $25(\mathrm{OH}) \mathrm{D} 12.5-25 \mathrm{nmol} / \mathrm{L}$ in the presence of elevated plasma alkaline phosphatase or elevated serum parathyroid hormone or low serum calcium. As there was a possibility that some infants had already started to receive vitamin $\mathrm{D}$ supplements before the diagnosis was given, we also included 11 patients with $25(\mathrm{OH}) \mathrm{D}$ 25-37 nmol/L of which all had X-ray findings consistent with rickets.

In cases of doubt, each case was discussed with a paediatric endocrinologist $(\mathrm{HJB})$ before the conclusion was made.

All 23 hospitals treating the identified patients were contacted. The unique personal identification number made it possible to link the information in NPR to the medical records at the hospitals.

To test gender differences and differences in number of cases per year, we used the $\chi^{2}$ test. As a denominator in the calculation of the incidence of rickets, we used the number of children aged $0-4$ years in the Norwegian population.

\section{RESULTS}

The flow of patient inclusion is displayed in figure 1. We identified 110 children under the age of 5 years in the NPR who had been diagnosed with active rickets (E55.0). We were able to review medical records from 18 of 23 hospitals, which constituted $85 \%$ of the identified patients. Of 94 reviewed medical records in patients with E55.0, the diagnosis of active rickets was confirmed in $54 \%(\mathrm{n}=51)$. Of these patients, nine were excluded as they were first diagnosed before 2008, leaving 42 patients with E55.0.

Of these, 39 patients were classified as having nutritional rickets, whereas rickets was linked to prematurity in three patients. In addition, three patients with the diagnosis of unspecified vitamin D deficiency (E55.9) were classified as having nutritional rickets, giving the final number of 42 patients. Four of the 42 patients were admitted due to seizure. They were between 1 and 3 months old and had very low $25(\mathrm{OH}) \mathrm{D}$ concentrations (11-15 nmol/L).

We did not include seven patients with an uncertain diagnosis of (nutritional) rickets.

As shown in table 1, mean age at the diagnosis of nutritional rickets was 1.40 years (range $0.1-3.5$ years), and $74 \%$ of the children were $1-2$ years at the time of diagnosis.

Fifty-seven per cent of the patients were boys (not statistically significantly different from girls, $\mathrm{p}=0.35$ ), and $48 \%$ were diagnosed during winter/early spring (NovemberApril) and 52\% during the rest of the year. Nearly all patients $(93 \%)$ had a non-western immigrant background and around $60 \%$ had a background from Asia. With regards to individual countries, $24 \%$ had a Pakistani background, $21 \%$ had an Iraqi background, whereas only $7 \%$ had an ethnic Norwegian background.

Apparently, there were variations in the number of patients with rickets from year to year. However, the numbers of cases were small and there was no overall 


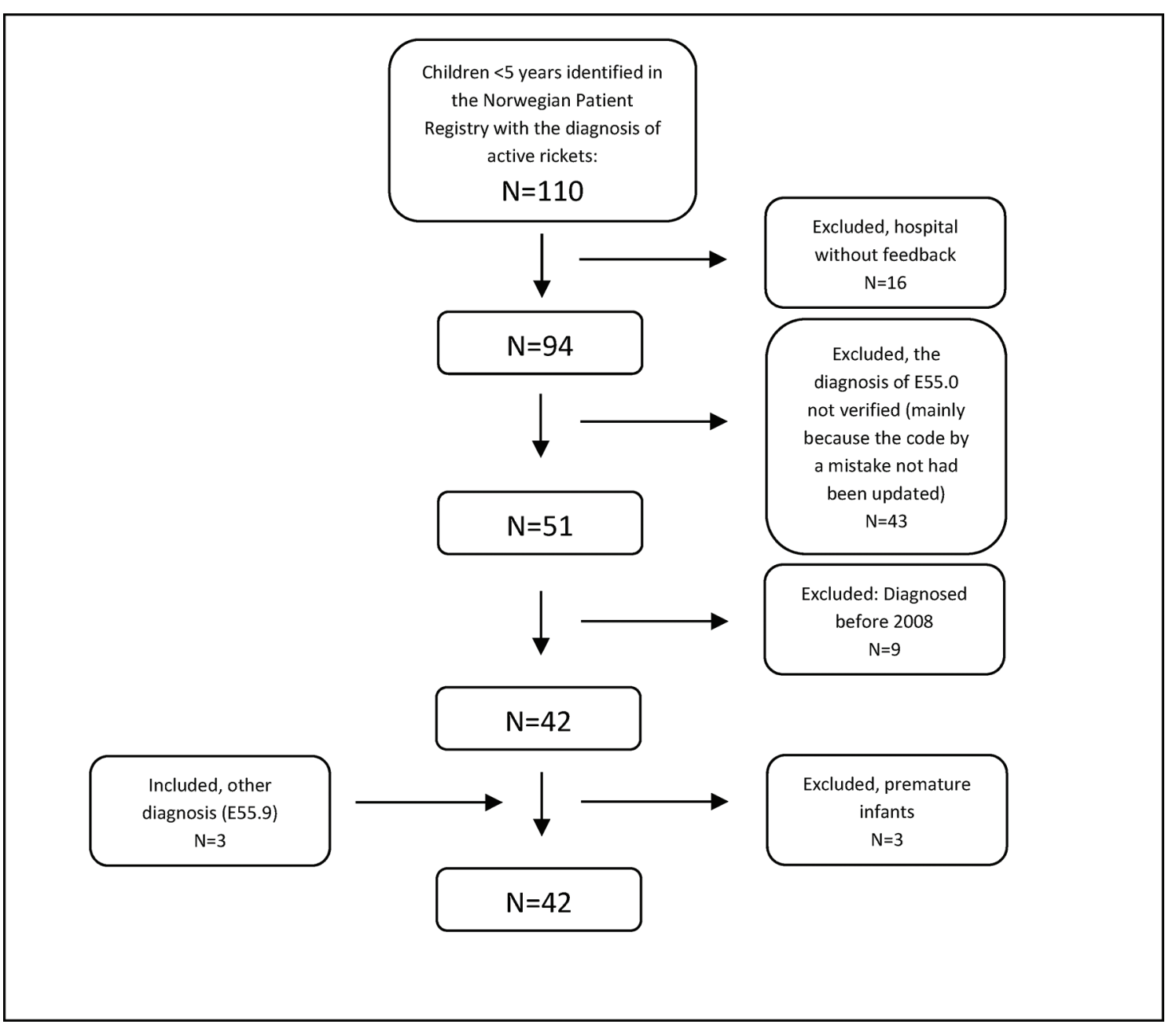

Figure 1 Flow of patient inclusion, nutritional rickets, Norway 2008-2012.

statistically significant difference between the years of diagnosis $(\mathrm{p}=0.56)$.

Around one-third of all children aged 0-4 years with an immigrant background from Asia and Africa are found in the Norwegian capital of Oslo. Although there were three to four cases each year in the period 2008-2010, there were no cases with nutritional rickets reported from Oslo in the period 2011-2012.

For 37 of the 42 children with nutritional rickets, information about $25(\mathrm{OH}) \mathrm{D}$ was available. Mean concentration was $17.9 \mathrm{nmol} / \mathrm{L}$, and $86.5 \%$ had concentrations $<30 \mathrm{nmol} / \mathrm{L}$.

Estimated incidence rate of rickets: According to Statistics Norway, the yearly average of children aged $0-4$ years in Norway in the period 2008-2012 was 303157 children. Of these, around 24000 children $(8 \%)$ had an Asian or African background.

Based on this, the incidence rate of rickets was estimated to be 3.1 (95\% CI 2.2 to 4.4) per 10000 person-years in children under the age of 5 years with an Asian or African background and 0.3 (95\% CI 0.2 to 0.4 ) per 10000 person-years in the total Norwegian population under the age of 5 years. This is a slight underestimate as we were not able to review $15 \%$ of the medical records. If each of the 16 children who were treated at hospitals without feedback had nutritional rickets, the incidence rate in the Norwegian population under the age of 5 years would be 0.4 per 10000 personyears.

\section{DISCUSSION}

The number of children with nutritional rickets in the Norwegian population during 2008-2012 was low and $93 \%$ occurred in children with a non-western immigrant background.

On average, eight cases of nutritional rickets were reported annually. This is considerably lower than the yearly average of 32 reported in the hospital enquiry for the 2-year period of 1998-1999. ${ }^{7}$ In addition, the number of children aged 0-4 years with an Asian or African background increased by around $75 \%$ from 2000 to 2012 . Although these two studies are not directly comparable, the risk of rickets seems to have declined substantially among immigrant children during recent years.

In the same period, several measures were introduced to prevent vitamin $\mathrm{D}$ deficiency and rickets. Based on the results from a cluster randomised trial, ${ }^{13}$ infants with a 
Table 1 Characteristics of 42 patients under the age of 5 years with nutritional rickets in Norway during 2008-2012

\begin{tabular}{lc}
\hline Age at diagnosis (years, mean (SD)) & $1.40( \pm 0.73)$ \\
$<1$ year, $\mathrm{n}(\%)$ & $10(24)$ \\
1 year, $\mathrm{n}(\%)$ & $21(50)$ \\
2 years, $\mathrm{n}(\%)$ & $10(24)$ \\
3 to $<4$ years, $\mathrm{n}(\%)$ & $1(2)$ \\
Gender, $\mathrm{n}(\%)$ & \\
Boys & $24(57.1)$ \\
Girls & $18(42.9)$ \\
Country background, $\mathrm{n}(\%)$ & $3(7.1)$ \\
Norway & $25(59.5)$ \\
Asia & $12(28.6)$ \\
Africa & $2(4.8)$ \\
Other/unknown & \\
Year of diagnosis, $\mathrm{n}(\%)$ & $6(14.3)$ \\
\hline 2008 & $10(23.8)$ \\
2009 & $12(28.6)$ \\
2010 & $7(16.7)$ \\
2011 & $7(16.7)$ \\
2012 & \\
\hline
\end{tabular}

non-western immigrant background are offered free vitamin $\mathrm{D}$ drops at child health clinics from the age of 4 weeks to 6 months. Since 2002, most infant cereals have been fortified with vitamin $\mathrm{D}$ and infant formula has been fortified with vitamin $\mathrm{D}$ for many years. In addition, at routine appointments at child health clinics during infancy, the public health nurses fulfil their long-standing commitment to inform mothers of the importance of vitamin D. According to a study among Norwegian-Somali and Norwegian-Iraqi infants, vitamin D supplements and fortified infant formula and cereals are frequently used. ${ }^{14}$

Another possible explanation for the low risk of rickets in Norwegian infants is that calcium intake in general is adequate. In the same study noted above, median daily calcium intake was $777 \mathrm{mg}$ in Norwegian-Somali and $633 \mathrm{mg}$ in Norwegian-Iraqi infants. ${ }^{15}$

However, nutritional rickets still occurs, even though it can be easily treated. Some groups are more exposed and around $50 \%$ of the patients had a background from two countries, Iraq and Pakistan.

Some weaknesses of the study should be mentioned. Although the NPR covers the entire Norwegian population, we were unable to confirm the rickets diagnosis in $15 \%$ of the patients as we did not receive feedback from all hospitals. In addition, the medical record reviews made locally at each hospital depended on available information in the medical records and reporting accuracy, and complete information was not always available. We might also have missed individuals who were given alternative diagnoses to E55.0. However, it is hard to see that this could impact our results substantially. Only 3 of 42 patients included were identified via our extended search (E55.9, E64.3 and E83.3) and these patients were diagnosed with unspecified vitamin D deficiency (E55.9) in the NPR. Another restriction is that the study was limited to Norway in the period 2008-2012, but the main finding of a low risk of rickets may apply to a similar population with similar measures to prevent vitamin D deficiency, including vitamin $\mathrm{D}$ supplementation and targeted vitamin D fortification for infants. However, awareness is needed as sudden changes, like a high influx of refugees, may alter the situation in segments of the child population. $^{16}$

\section{CONCLUSION}

The number of children with nutritional rickets in Norway remained low in the period 2008-2012, and 93\% of the children had a non-western immigrant background.

Acknowledgements We thank the physicians at the individual hospitals for reviewing the medical records and Julie Whittle Johansen for proof-reading the manuscript.

Transparency declaration The lead author (HEM) affirms that the manuscript is an honest, accurate, and transparent account of the study being reported; that no important aspects of the study have been omitted; and that any discrepancies from the study as planned have been explained.

Contributors HEM, IAB, AAM and HJB conceived the study. HEM, KS, IAB and HJB collected the data. HEM analysed the data and drafted the article. All authors contributed in the interpretation of the findings, critically revised the paper for important intellectual content and approved the final version. HEM is the guarantor.

Funding This study was funded by the Norwegian Directorate of Health. The sponsor had no influence on the preparation, review or approval of the manuscript. Competing interests None declared.

Ethics approval The study did not include any involvement from the patients and was approved by the Regional Committee for Medical and Health Research Ethics (2013/2370/REK sør-øst D).

Provenance and peer review Not commissioned; externally peer reviewed.

Data sharing statement The Regional Committee for Medical and Health Research Ethics judged these data to be highly sensitive. The data can therefore not be shared unless a separate query is sent to the ethical committee and the data owners.

Open Access This is an Open Access article distributed in accordance with the Creative Commons Attribution Non Commercial (CC BY-NC 4.0) license, which permits others to distribute, remix, adapt, build upon this work non-commercially, and license their derivative works on different terms, provided the original work is properly cited and the use is non-commercial. See: http://creativecommons.org/ licenses/by-nc/4.0/

(C) Article author(s) (or their employer(s) unless otherwise stated in the text of the article) 2017. All rights reserved. No commercial use is permitted unless otherwise expressly granted.

\section{REFERENCES}

1. Munns CF, Shaw N, Kiely M, et al. Global consensus recommendations on prevention and management of nutritional rickets. J Clin Endocrinol Metab 2016;101:394-415.

2. Lips P. Worldwide status of vitamin D nutrition. J Steroid Biochem Mol Biol 2010;121:297-300.

3. Holvik K, Meyer HE, Haug E, et al. Prevalence and predictors of vitamin $\mathrm{D}$ deficiency in five immigrant groups living in Oslo, Norway: the Oslo Immigrant Health Study. Eur J Clin Nutr 2005;59:57-63.

4. Meyer HE, Falch JA, Søgaard AJ, et al. Vitamin D deficiency and secondary hyperparathyroidism and the association with bone mineral density in persons with Pakistani and Norwegian background living in Oslo, Norway. The Oslo Health Study. Bone 2004;35:412-7. 
5. Madar AA, Stene LC, Meyer HE. Vitamin D status among immigrant mothers from Pakistan, Turkey and Somalia and their infants attending child health clinics in Norway. Br J Nutr 2009;101:1052-8.

6. Statistics Norway. Immigrants and Norwegian-born to immigrant parents Oslo. 2016. https://www.ssb.no/statistikkbanken/selecttable/ hovedtabellHjem.asp?KortNavnWeb=innvbef\&CMSSubjectArea= befolkning\&PLanguage $=1$ \&checked=true 2016.

7. Brunvand L, Brunvatne R. [Health problems among immigrant children in Norway]. Tidsskr Nor Laegeforen 2001;121:715-8.

8. Beck-Nielsen SS, Brock-Jacobsen B, Gram J, et al. Incidence and prevalence of nutritional and hereditary rickets in southern Denmark. Eur J Endocrinol 2009;160:491-7.

9. Thacher TD, Fischer PR, Tebben PJ, et al. Increasing incidence of nutritional rickets: a population-based study in Olmsted County, Minnesota. Mayo Clin Proc 2013;88:176-83.

10. Goldacre M, Hall N, Yeates DGR. Hospitalisation for children with rickets in England: a historical perspective. Lancet 2014;383:597-8.
11. Ahmed SF, Franey $\mathrm{C}, \mathrm{McDevitt} \mathrm{H}$, et al. Recent trends and clinical features of childhood vitamin $D$ deficiency presenting to a children's hospital in Glasgow. Arch Dis Child 2011;96:694-6.

12. Prentice A. Nutritional rickets around the world. J Steroid Biochem Mol Biol 2013;136:201-6.

13. Madar AA, Klepp KI, Meyer HE. Effect of free vitamin D(2) drops on serum 25-hydroxyvitamin $D$ in infants with immigrant origin: a cluster randomized controlled trial. Eur J Clin Nutr 2009;63:478-84.

14. Grewal NK, Andersen LF, Sellen D, et al. Breast-feeding and complementary feeding practices in the first 6 months of life among Norwegian-Somali and Norwegian-Iraqi infants: the InnBaKost survey. Public Health Nutr 2016;19:703-15.

15. Grewal NK, Andersen LF, Kolve CS, et al. Food and nutrient intake among 12-month-old Norwegian-Somali and Norwegian-Iraqi infants. Nutrients 2016;8:602.

16. Thacher TD, Pludowski P, Shaw NJ, et al. Nutritional rickets in immigrant and refugee children. Public Health Rev 2016;37:3. 